\title{
EXPLORING ANTECEDENTS AND CONSEQUENCES OF BURNOUT IN A CALL CENTRE
}

\author{
WILLIE A VISSER \\ SEBASTIAAN ROTHMANN \\ WorkWell: Research Unit for People, Policy and Performance \\ North-West University \\ South Africa \\ Correspondence to: Sebastiaan Rothmann \\ e-mail: ian@ianrothmann.com
}

\begin{abstract}
The aim of this study was to investigate the relationship between six characteristics of call centre work environments, burnout, affective commitment and turnover intentions. These characteristics were competing management goals, work overload, electronic performance monitoring, lack of career opportunities, lack of skill variety and emotional labour. A convenient sample of employees $(N=146)$ was obtained from a call centre. Multiple regression analysis showed that work overload, lack of career opportunities, skill variety and emotional labour were the most important predictors of burnout. Burnout had a direct effect on turnover intentions. Affective commitment partially mediated the relationship between burnout and turnover intention.
\end{abstract}

Keywords: burnout, antecedents, call centres, affective commitment, turnover intention

Within the service industry, call centres have become a very popular method of service delivery, mostly because of financial benefits (cost savings implications) to the organisations that make use of them. Call centres eliminate the need for extensive, and expensive, branch networks with face-to-face service interaction. A large proportion of service work is now done through call centres, which explains why increasing numbers of people are employed in these centres (Deery \& Kinnie, 2004). Comparable growth, both in the number of call centres and people that work in them, has also been reported in the UK, where it is estimated that $2,3 \%$ of the total workforce are employed in call centres (Taylor \& Bain, 1999). Approximately $3 \%$ of the USA and $1 \%$ of the European workforce are employed in call centres (Deery \& Kinnie, 2004).

A similar pattern of call centre growth is seen in South Africa. It is estimated that there are approximately 250 call centres in this country, with an estimated growth of $20 \%$ per year. In South Africa, as in the rest of the world, call centres are fast replacing the traditional service channel of branch infrastructures in the financial services sector, which accounts for approximately $35 \%$ of all call centres in South Africa (Briggs, 1998).

In the service economy, specifically within call centres, a special type of service employee needs to be mentioned. They are referred to as customer service representatives (Holdsworth \& Cartwright, 2003). They occupy boundary-spanning roles in representing the organisation to the customer and mostly perform emotional labour, i.e. a form of emotional regulation where in which employees are expected to display certain emotions as part of their job, and to promote organisational goals (Grandey, 2000). Customer service representatives are highly susceptible to elevated levels of stress and burnout, more so than in any other work environment. The work of a customer service representative is seen as one of the ten most stressful jobs in the present-day world economy (Holdsworth \& Cartwright, 2003; Malhotra \& Mukherjee, 2004; Singh \& Goolsby, 1994).

In recent studies, several key factors were identified that are commonly associated with burnout, low organisational commitment and turnover intention among customer service representatives. These are: work overload, monitoring and surveillance of employees, competing management goals, upward career movement, lack of skill variety, and emotional labour (Cordes \& Dougherty, 1993; Deery et al., 2002; Deery \& Kinnie, 2004; Holman, 2004; Singh, 2000; Zapf, Isic, Bechtoldt \& Blau, 2003).

Since the effectiveness and health of customer care representatives are of the utmost importance in order to deliver quality service, burnout, affective commitment and turnover intention should be investigated. It is essential to determine burnout, organisational commitment, and turnover intention of customer service representatives and antecedents thereof and to search for variables that lessen the impact of these stressors.

Given theabove, thelack of empirical research that systematically investigates burnout, organisational commitment and turnover intention in call centres in South Africa is a concern. The aims of this study were, firstly, to investigate the contribution of six central characteristics (antecedents) of call centre work environments to burnout, and secondly, to determine whether burnout affected turnover intentions directly or indirectly.

\section{Burnout in call centre work environments}

Burnout can be seen as a chronic affective response syndrome, a type of stress that develops in response to stressful working conditions (Cordes \& Dougherty, 1993). It does not develop overnight. When people experience burnout they usually experience a gradual sense of loss that develops over an extended period of time. With the onset of burnout, an engaged, positive and energetic relationship with one's work progressively turns into disengagement, a loss of energy, limited commitment and a sense of ineffectiveness, which, over time, becomes real in the form of reduced accomplishment (Maslach \& Leiter, 1997).

The most accepted definition of the condition describes burnout as consisting of three separate but interrelated constructs, namely emotional exhaustion, depersonalisation and reduced personal accomplishment (Maslach, Schaufeli \& Leiter, 2001). The first of these constructs, emotional exhaustion, is thought to be the most important, and is the first response to develop. It is characterised by feelings of emotional depletion, extreme tiredness, a lack of energy and a feeling of being drained of emotional resources to cope with continuing demands (Cordes \& Dougherty, 1993; Maslach et al., 2001; Schutte, Toppinen, Kalimo \& Schaufeli, 2000). When employees reach this point of 
extreme tiredness, they act to conserve their levels of energy. To regulate their energy resources, they reduce their emotional and cognitive involvement with the work; in other words, they withdraw from their work. This leads to the second component of burnout, namely depersonalisation (Maslach et al., 2001). Depersonalisation can be seen as a coping response that will protect the employee from further emotional depletion. This form of coping has serious implications for a company that makes use of service workers to provide their services. When service employees use depersonalisation as a form of coping in response to high levels of emotional exhaustion, they tend to be less responsive to, and involved with, the needs of their customers (Maslach et al., 2001; Singh, 2000; Singh \& Goolsby, 1994). In the final phase of burnout - reduced personal accomplishment - employees compare their current levels of competence with their previous levels of competence before emotional exhaustion and depersonalisation had set in. In this self-evaluation, they see that they are not as competent and efficient as they used to be and feelings of incompetence, lack of achievement and lower productivity follow (Cordes \& Dougherty, 1993; Maslach, 2001; Schutte et al., 2000).

Traditionally, burnout has been seen as an "individual weakness", without consideration for the role of the work environment in developing burnout. According to Maslach and Leiter (1997), this reasoning is flawed in that it only looks at the individual and not at the individual within the working context. Research on burnout indicates that the environment within which individuals find themselves, specifically the characteristics of the work environment, are more related to burnout than to personal and or personality factors (Leiter \& Maslach, 1988; Maslach \& Leiter, 1997).

This point of view is also valid when it comes to call centres. In general, call centres are not seen as particularly pleasant workplaces. They have been given many different names such as "electronic sweatshops", "dark satanic mills" and "assembly lines in the head" (Deery \& Kinnie, 2004; Taylor \& Bain, 1999). Various studies conducted by researchers on the call centre work environment indicate that many different variables inherent to the nature of call centre work and call centre work environments have been linked to the development of burnout. These include high levels of workload and pressure from management to maximise client throughput, linked to contradictory demands from management with regard to quality client service as well as client throughput; tenure, the repetitive nature of the work, lack of task variety, management focus on throughput, lack of supervisor and co-worker support, lack of training to deal with job requirements, customer service representatives' perception that customers are becoming more difficult to satisfy, tightly scripted telephone conversations; emotional demands of labour, continuous monitoring of performance, perceived lack of job and promotion opportunities, number of calls taken per day, pressure from management to reduce wrap-up time, role conflict, role ambiguity, and lack of job control (Deery, Iverson \& Walsh, 2002; Deery \& Kinnie, 2004; Holman, 2004; Singh, 2000; Singh \& Goolsby, 1994; Taylor \& Bain, 1999; Wallace, Eagleson \& Waldersee, 2000).

The researchers will now discuss factors that could lead to burnout in call centres, namely work overload, monitoring and surveillance of employees, competing management goals, lack of upward career movement, lack of skill variety, and emotional labour.

\section{Work overload}

There is a well-established link between heavy work demand in the form of work overload and the development of burnout (Maslach et al., 2001). Work overload is directly related to the development of emotional exhaustion (Cordes \& Dougherty, 1993). Some of the more common aspects of work overload involve high levels of client contact (high frequency of contact), not being able to take a break between calls, receiving calls on a continuous basis, perceived high target levels, time pressure (inability to do all the work in the time allocated per customer and brief call cycles), pressure to reduce wrap-up time, and continuous versus alternating demands (Cordes \& Dougherty, 1993; Deery et al., 2002; Deery \& Kinnie, 2004; Holman, 2004; Singh, 2000; Taylor, Hyman, Mulvey \& Bain, 2002; Zapf, Isic, Bechtoldt \& Blau, 2003).

\section{Monitoring and surveillance of employees}

Monitoring and surveillance of employees are seen as very prominent and invasive call centre practice, specifically in call centres with a strategic focus on maximising efficiency and customer throughput at the lowest possible unit cost per customer interaction. In call centres, management emphasis is on monitoring and measuring employees, and technology is used as a control device to manage the workplace, to ensure compliance with work procedures, to monitor the speed of production, to regulate the level of downtime, to assess the quality of customer interactions, to reduce variability in service delivery and to enforce high production standards (Deery et al., 2004; Holdsworth \& Cartwright, 2002; Holman, 2004; Taylor et al., 2002).

Monitoring and surveillance of employees through technology provide management with productivity statistics, which often form the basis for performance evaluation (Holdsworth \& Cartwright, 2002). This information can be applied, firstly, as a punitive measure to enforce performance standards: the information gained from the monitoring process is used for disciplinary purposes and is perceived as threatening because it directly affects remuneration. When used in a punitive manner, monitoring is viewed as a job demand in its own right and is associated with negative employee well-being. Secondly, the information gained through the monitoring process can be used for furthering the employee's development. In such cases, performance statistics are used as feedback, to enable the employee to improve performance and to upgrade skills levels. When viewed in this way, it can actually become a tool through which the well-being of employees can be improved (Holman, 2004; Taylor \& Bain, 1999).

Excessive long-term monitoring can have a negative effect on employees. Electronic performance monitoring is highly associated with stress (Holdsworth \& Cartwright, 2002; Wallace et al., 2000). It causes employees to become more depressed and to develop higher levels of anxiety, which may in turn cause them to devote more of their cognitive resources to dealing with the anxiety. Employee monitoring is therefore also linked to higher levels of emotional exhaustion, specifically in the case of employees who dislike having their performance scrutinised continuously (Holman, 2004).

\section{Competing management goals}

Competing management goals is a type of role conflict endemic to call centres. It is seen as a source of stress by call centre employees (Deery \& Kinnie, 2004). This conflict finds its expression in dual goal demands when management on the one hand focuses on and espouses quality service and high levels of customer satisfaction, whilst, on the other hand, demanding high levels of customer processing and throughput. Employees are constantly monitored and pressurised to ensure high levels of productivity in the form of high call volumes, brief talk times with customers and short wrap-up times, while the quality of their customer interactions is simultaneously monitored with the purpose of improving customer service (Wallace et al., 2000). Although management may talk about the importance of both of these goals, the perception of call centre employees is that the focus is more on throughput than on customer service. This creates internal conflict for employees who see these dual goals (demands) as incompatible and incongruent. The pressure 
for higher productivity in the form of call volumes and brief talk times with clients impedes the ability and will to provide quality customer service. Trying to fulfil both these goals results in high levels of frustration and emotional distress. It is therefore postulated that conflicting management goals are positively associated with the development of burnout (Deery et al., 2002; Deery \& Kinnie, 2004; Holman, 2004; Wallace et al., 2000).

\section{Upward career movement}

Upward career movement is seen as an organisational resource that acts as a buffer against the development of stress. A lack of upward career movement is a predictor of emotional exhaustion; if it is perceived to be present in organisations, it will be associated with lower levels of burnout (Cordes \& Dougherty, 1993; Deery et al., 2002). When people experience greater upward career movement relative to their peers, it may serve as a form of feedback indicating that they are making a positive contribution to the organisation in the form of valued accomplishments. Promotions are also associated with reduced client contact, which removes one of the necessary conditions for the development of emotional exhaustion by reducing the frequency and intensity of client interaction (Cordes \& Dougherty, 1993; Maslach et al., 2001). Call centres are mostly designed to be cost effective substitutes for face-to-face branch networks. To achieve cost effectiveness, call centres are designed to have a flat organisational structure, which leads to the perception of limited career and developmental opportunities. In general, call centres are perceived to be low status "deadend" jobs (Deery et al., 2004; Taylor \& Bain, 1999).

\section{Lack of skill variety}

Call centre jobs are often compared to factory jobs or assembly lines based on Tayloristic principles of job design (Zapf et al., 2003). They can be highly routinised, with a lack of skill variety designed into the work. The work is often perceived as repetitive in nature: agents do the same thing over and over again. The characteristics of the work that contribute to the assembly line perception are: conversations are forced to be brief and routinised because of being scripted and controlled, the work is often viewed as unskilled work as it involves a low level of complexity, customer service representatives have no opportunity to use their skills and abilities, the division of labour only allows a customer service representative to do a small part of the work before it is passed on to the back office where specialists deal with the queries. The work, lastly, is seen as monotonous, as customer service representatives are required to perform the same activity over and over again. Experienced monotony is one of the most frequently cited reasons when employees resign (Frenkel, Tam, Korczynski \& Shire, 1998; Grebner et al., 2003; Taylor \& Bain, 1999; Taylor et al., 2002; Wallace et al., 2000; Zapf et al., 2003). Research has indicated that a lack of complexity and low utilisation of qualifications and skills are related to low levels of affective commitment, while experienced monotony, low variety and low levels of complexity predict employees' intentions to quit (Grebner et al., 2003).

\section{Emotional labour}

Working in the service industry and in call centres involves the performance of emotionally taxing labour. Providing the particular service requires the employee's frequent and competent interaction with customers requiring some form of service. Such high levels of social interaction involve the performance of emotional labour (Erickson \& Wharton, 1997). Service employees engaged in emotional labour deal directly with the customers of their organisations and are in frequent face-to-face or voice-to-voice contact with them (Kruml \& Geddes, 2000). As it is expected that face-to-face customer contact through branch networks will be completely replaced by call centres in the future, voice-to-voice customer contact will become the most salient form of customer contact (Malhotra \& Mukherjee, 2004). Service organisations try to direct and control the quality of service interactions so that employees will create a positive emotional state in the recipient of the service. This requires that the behaviour of employees conform to organisationally established norms (Morris \& Feldman, 1996).

Emotional labour can thus be defined as the expression of appropriate emotions, as defined by the organisation, during interaction with customers. Employees are expected to express socially desired emotions, to appear happy and eager to serve the customer, to display positive emotions and suppress negative emotions (Deery et al., 2002; Maslach et al., 2001). This can be seen as a type of job demand (Zapf et al., 2003). The important factor playing a role in the development of burnout is the emotional dissonance component of emotional labour. Emotional dissonance develops when employees display positive emotions but feel quite differently within themselves. It makes them feel inauthentic (Deery et al., 2004; Lewig \& Dollard, 2003; Zapf et al., 1999). Call centre employees, and customer service representatives specifically, are more prone to burnout for they mostly perform emotional labour and occupy boundary-spanning roles in representing the organisation to the customer (Singh \& Goolsby, 1994).

The following hypothesis is formulated regarding the relationship between antecedents in a call centre and burnout:

Hypothesis 1: Work overload, monitoring and surveillance of employees, competing management goals, lack of upward career movement, lack of skill variety, and emotional labour predict burnout.

\section{Burnout, organisational commitment and turnover}

In the following sections the researchers will discuss the relationships between burnout, organisational commitment and turnover.

\section{Organisational commitment and burnout}

Organisational commitment is viewed as a psychological state that will define and influence an employee's relationship with his or her organisation (Meyer, 2001). This defined relationship will determine decisions to stay with or leave the organisation. Organisational commitment has been defined in many ways, but one of the more influential perspectives comes from the work of Meyer and Allen, who conceptualise organisational commitment as consisting of three components, namely affective commitment, continuance commitment and normative commitment (Malhotra \& Mukherjee, 2004; Meyer, 2001; Somers, 1995). For the purpose of this study, the focus will be on affective commitment, which is defined as: “... [the] employee's emotional attachment to, identification with, and involvement in the organisation" (Malhotra \& Mukherjee, 2004, p. 166).

Affective commitment refers to the emotional attachment of an employee to an organisation (Meyer, 2001). Intuitive reasoning would suggest that emotional exhaustion, which is an affective response from people towards their working environment, would influence their emotional attachment to their organisation. It was found that emotional exhaustion tends to erode organisational commitment (Lee \& Ashforth, 1996). Organisational commitment is a function of the characteristics of the job and the work environment rather than a function of personal characteristics (Meyer, 2001).

The following hypothesis is formulated regarding the relationship between burnout and organisational commitment:

Hypothesis 2: Burnout in call centres significantly predicts low affective commitment. 


\section{Burnout and turnover}

Turnover intentions can be described as an inclination to leave an organisation voluntarily and is seen as the best predictor of actual turnover. Thus, turnover intentions can be used as a reliable indicator of actual quitting (Janssen, De Jonge \& Nijhuis, 2001; Maertz \& Campion, 2001). In general, high staff turnover is considered to have a negative influence on organisations. Associated negative consequences of high turnover levels are added staffing and training costs, operational disruption and, ultimately, lost production capacity as well as lower levels of customer service (Maertz \& Campion, 2001). It is therefore important to understand the predictors of turnover to enable the management of a call centre to manage the impact on the organisation.

The average turnover in call centres is high. It has been reported that call centres in the UK face a turnover rate of $49 \%$ or more, which means that nearly half of their staff resign in the course of a year (Malhotra \& Mukherjee, 2004). A similar finding was made by Deery et al. (2004), namely that the annual turnover rate in call centres in the UK was in the region of $30 \%$. Turnover rates for call centres are reported to be above average in comparison with equivalent office-type working environments (Holdsworth \& Cartwright, 2003).

Call centre work has been highly associated with stress and burnout, with resultant high levels of staff turnover (Holdsworth \& Cartwright, 2003). Emotional exhaustion was found to be a strong predictor of both organisational commitment and turnover intentions. When individuals experience higher levels of emotional exhaustion, they are more likely to leave their jobs, and positive correlations have also been found between emotional exhaustion and turnover intentions. Several studies reviewed by Burke and Richardsen (2001) have found that turnover intention was significantly related to burnout.

The following hypothesis is formulated regarding the relationship between burnout and turnover intention:

Hypothesis 3: Burnout in call centres significantly predicts turnover intention.

\section{Organisational commitment and turnover intention}

When employees experience lower levels of organisational commitment, they will be more prone to leave their organisations. Meyer (2001) showed that affective commitment, specifically, correlates negatively with turnover intentions and/or actual turnover (Meyer, 2001). With higher levels of organisational commitment, turnover intentions are reduced (Low, Cravens, Grant \& Moncrief, 2001). A study investigating the relationship between the organisational commitment of salespeople (who fulfil a boundary-spanning role in the same way as customer service representatives) and their turnover intentions, found support for the notion that higher levels of organisational commitment have a negative impact on the intention to leave (Low et al., 2001). It has also been found that burnout plays a mediating role between organisational demands (e.g. work overload) and organisational commitment. This mediating effect is influenced specifically by emotional exhaustion (Burke \& Richardsen, 2001). A negative relationship between affective commitment and turnover intentions was reported in a call centre study by De Ruyter (2001, cited in Bakker, Demerouti \& Schaufeli, 2003).

The following hypothesis is formulated regarding the relationship between burnout, affective commitment and turnover intentions:

Hypothesis 4: Organisational commitment mediates the relationship between burnout and turnover intentions.

\section{RESEARCH DESIGN}

\section{Research approach}

A cross-sectional survey design was used in this study. This design is suitable for describing the relationships between variables. Questionnaires were used to gather data in a field survey.

\section{Research method}

Participants

A convenient sample of customer service representatives was obtained from the call centre of a large financial company in the Western Cape. These participants were selected because they worked in a call centre which represents the typical problems experienced by customer service representatives. This call centre was mostly inbound, with employees taking service-related calls and queries from customers. Only the customer service representatives of this call centre took part in the research and back-office workers were excluded. Of the 200 surveys handed out, $146(N=146)$ were returned, giving a response rate of $73 \%$. Table 1 gives a summary of the key characteristics of the sample.

Table 1 shows that the sample consisted mostly of white $(41.8 \%)$ and coloured $(44.5 \%)$ employees. More than two-thirds $(70.1 \%)$ of participants were female, almost all participants were either English (69.9\%) or Afrikaans (27.4\%) speaking, and the age groups $31-40$ years and $20-30$ years were best represented $-42.2 \%$ and $35.6 \%$ respectively. The majority of participants had either an educational level of grade $12(46.6 \%)$ or higher education in the form of a technikon qualification $(43.8 \%)$. Most participants had been employed in this particular call centre for more than two years $(63.7 \%)$, while $14,4 \%$ had been employed there for between 1 and 2 years, and 20.5\% had less than one year's experience in this call centre.

\section{Measuring instruments}

All the measuring instruments, apart from the Affective Commitment and Turnover Intention scales, were specifically developed for this study. The items in the questionnaire, with the exception of the Burnout Scale, were measured with a fivepoint Likert-type scale, with responses ranging from 1 (strongly disagree) to 5 (strongly agree). Respondents had to indicate the extent of their agreement with each statement. The reliability of each scale was calculated using the Cronbach alpha coefficient.

TABLE 1

Characteristics of participants $(n=146)$

\begin{tabular}{llrr}
\hline ITEM & CATEGORY & FREQUENCY & PERCENTAGE \\
\hline Race Group & White & 61 & 41.8 \\
& Black & 8 & 5.5 \\
& Coloured & 65 & 44.5 \\
& Indian & 2 & 1.4 \\
Missing values & 10 & 6.9 \\
& Male & 40 & 27.4 \\
& Female & 102 & 70.1 \\
Language & Missing values & 4 & 2.5 \\
& Afrikaans & 40 & 27.4 \\
& English & 102 & 69.9 \\
Age & Missing values & 4 & 2.7 \\
& 20-30 years & 52 & 35.6 \\
& 31-40 years & 63 & 42.2 \\
& 41-50 years & 19 & 13.0 \\
& 51 and older & 9 & 6.0 \\
Educational Level & Missing values & 3 & 3.2 \\
& Grade 12 & 68 & 46.6 \\
& Technikon qualification & 64 & 43.8 \\
& University degree & 6 & 4.1 \\
& College qualification & 6 & 4.1 \\
& Missing values & 2 & 1.4 \\
Years of Employment & Less than one year & 30 & 20.5 \\
& $1-2$ years & 21 & 14.4 \\
& More than two years & 93 & 63.7 \\
& Missing values & 2 & 1.4 \\
\hline
\end{tabular}


The reliabilities of the scales varied between $\alpha=0.84$ and $\alpha=0.94$ and were all above the recommended alpha coefficient of 0.70 (Nunnally \& Bernstein, 1994).

A seven-item burnout scale ( $\alpha=0.93$ ) was developed to measure burnout in call centres. The items were developed to capture the emotional exhaustion component of the burnout construct as this was seen as the most relevant and important part of burnout. Item development was based on theory as well as extensive qualitative interviews with 40 customer service representatives and their immediate team leaders. The response format ranged from 0 to 6 and was as follows: never (0), sporadic (1), now and then (2), regularly (3), often (4), very often (5), daily (6). Respondents were asked to indicate how often (if ever) they experienced each of the situations described in statements. Sample items were: "I feel tired - worn out from my work", and "I feel my work depletes my emotional strength."

Turnover intentions were measured using a four-item scale based on the work of Mobley, Homer and Hollingsworth (1978) as reported in Bozeman and Perrewé (2001) and Mowday, Steers and Porter (1979). Four of the five items were used. Two of the negatively worded items were changed into positively worded items. For example, "I am seriously considering leaving my job" was changed to "I'm not thinking about quitting my job at the present moment."

Affective commitment was measured using a five-item scale based on Allen and Meyer's (1990) three-component model of commitment as reported in Malhotra et al. (2004) and Dunham, Grube and Castañeda (1994). Three of the negatively worded items were changed to positively worded items. For example, the item "I feel emotionally attached to this organisation." was changed to "I do not feel emotionally attached to this organisation."

The independent variables were measured with one questionnaire consisting of six subscales. The subscales were work overload, electronic performance monitoring, lack of career opportunities, lack of skill variety, emotional labour, and competing management goals. Work overload refers to the experience of quantitative overload. It measures the employees' perceptions of their workload, whether they have enough time to wrap up a call, whether they feel that they work under continuous time pressure and whether they feel that the pace of work is too strenuous for them. Work overload was measured using six items and included items like: "I feel that the pace of work is too fast". Electronic performance monitoring was measured with five items measuring employees' perceptions about constant monitoring. It included items like: "I experience the way in which we do performance monitoring as invasive." The development of these items was based on the work of Holman (2004). Lack of career opportunities was operationalised by five items. It measured the views of employees concerning future career and promotion prospects within the call centre. Example item: "There are few career opportunities in the call centre." Five items measured lack of skill variety. It captured the views of the customer service representatives about whether their work provided them with a sufficient variety of skills, whether they saw their work as a challenge and whether their work utilised their skills and abilities. Example item: "I am bored at work." Emotional labour was operationalised through four items. It measured the emotional dissonance component of emotional labour as it was thought to play a major role in the development of emotional exhaustion (Deery et al., 2004; Lewig \& Dollard, 2003; Zapf et al., 1999). The scale included items like: "I often have to keep myself from expressing my true feelings." Competing management goals was assessed with five items. It measured the degree to which the customer service representatives perceived management's espoused goals and focus to be in conflict with one another. Example item: "Management talks a lot about good customer service, but in the end the really important thing is the average number of calls taken."

\section{Research procedure}

To improve the response rate, management agreed to reschedule the customer service representatives over the course of two weeks to free them for 45 minutes to complete the survey. The surveys were completed anonymously in small groups.

\section{Statistical analysis}

All statistical analysis was carried out with SPSS version 14 (SPSS, 2007). Firstly, Cronbach alpha coefficients $(\alpha)$ for each of the scales were calculated to assess the internal consistency. Secondly, Pearson correlation coefficients were used to examine the relationships between the six salient work characteristics within call centres and the dependent variables of burnout, affective commitment and turnover intentions. Thirdly, correlational analysis was supplemented with multiple regression analysis to test the relative contribution of each variable to burnout, and to test for possible mediating effects. Mediating effects were tested in line with the described procedure as set out by Baron and Kenny (1986). According to them, three different regression equations should be calculated and three conditions should be adhered to. In the first regression, the independent variable and the mediator must be significantly related. In the second regression, the dependent variable and the independent variable must be significantly related. In the third regression, both the independent variable and the mediator are regressed on the dependent variable. In this regression, the effect of the independent variable on the dependent variable should be less than in the second regression.

\section{RESULTS}

The questionnaire measuring the independent variables was subjected to a principal component (varimax) factor analysis. Six factors were retained. They accounted for $66 \%$ of the variance. The factor names, eigenvalues and percentages of the variance that they explained (in brackets), are reported in descending order. The first factor was competing management goals (eigenvalue: 9.77, percentage variance: $33 \%$ ); the second factor, work overload (eigenvalue: 2.80 , percentage variance: $9 \%$ ); the third factor,electronicperformancemonitoring(eigenvalue: 2.40, percentage variance: $8 \%$ ); the fourth factor, lack of career opportunities (eigenvalue: 1.70, percentage variance: $6 \%$ ); the fifth factor, lack of skill variety (eigenvalue: 1.61, percentage variance: $5 \%$ ); and the sixth factor was emotional labour (eigenvalue: 1.48 , percentage variance: $5 \%$ ).

Descriptive statistics, the calculated Cronbach alpha coefficients of each of the measurement scales and the Pearson correlation coefficients of the variables used in the study are reported in Table 2.

As seen in Table 2, the Cronbach alpha coefficients of the measurement scales varied between 0.84 and 0.94 , which is higher than the recommended guideline of 0.70 (Nunnally \& Bernstein, 1994).

From Table 2 it is evident that burnout is positively and significantly related to lack of career opportunities $(r=0.61$, large effect), work overload ( $r=0.60$, large effect) and lack of skill variety ( $r=0.53$, large effect). In descending order, the following independent variables had medium effects in their association with burnout: emotional labour $(r=0.43)$, electronic performance monitoring $(r=0.43)$ and competing management goals $(r=0.34)$.

All the independent variables were negatively related to affective commitment, as expected. With regard to the 
TABLE 2

Descriptive statistics and product-moment correlations

\begin{tabular}{|c|c|c|c|c|c|c|c|c|c|c|c|c|}
\hline SCALE & ITEMS & MEAN & SD & $\alpha$ & 1 & 2 & 3 & 4 & 5 & 6 & 7 & 8 \\
\hline 1. Competing Management Goals & 5 & 15.89 & 4.79 & 0.88 & - & - & - & - & - & - & - & - \\
\hline 2. Work Overload & 6 & 17.55 & 5.31 & 0.87 & $0.49 *++$ & - & - & - & - & - & - & - \\
\hline 3. Electronic Performance Monitoring & 5 & 14.68 & 4.5 & 0.85 & $0.43^{*}+$ & $0.52^{*++}$ & - & - & - & - & - & - \\
\hline 4. Lack of Career Opportunities & 6 & 20.32 & 5.19 & 0.87 & $0.40^{*}+$ & $0.52^{*++}$ & $0.49^{*++}$ & - & - & - & - & - \\
\hline 5. Lack of Skill Variety & 5 & 15.15 & 4.38 & 0.84 & $0.33^{*}+$ & $0.40^{*}+$ & $0.41^{*}+$ & $0.57^{*++}$ & - & - & - & - \\
\hline 6. Emotional Labour & 4 & 11.91 & 3.69 & 0.84 & 0.12 & $0.36^{*}+$ & $0.33^{*}+$ & $0.32^{*}+$ & $0.25^{\star}$ & - & - & - \\
\hline 7. Burnout & 7 & 14.65 & 9.40 & 0.93 & $0.34^{*}+$ & $0.60^{*}++$ & $0.43^{*}+$ & $0.61^{*++}$ & $0.53^{*++}$ & $0.43^{*}+$ & - & - \\
\hline 8. Turnover Intentions & 4 & 10.77 & 4.53 & 0.94 & $0.27^{*}+$ & $0.44^{*++}$ & $0.32^{*}+$ & $0.66^{*}++$ & $0.46^{*}++$ & $0.31^{*}+$ & $0.64^{*++}$ & - \\
\hline 9. Affective Commitment & 5 & 16.32 & 4.70 & 0.88 & $-0.40^{*}+$ & $-0.35^{*}+$ & $-0.30^{*}+$ & $-0.46^{*}++$ & $-0.39^{*}+$ & $-0.29^{*}+$ & $-0.50^{*}++$ & $-0.51^{*}++$ \\
\hline
\end{tabular}

* Correlation is significant at the 0.01 level (1-tailed)

$r>0.30$ - practically significant (medium effect)

TABLE 3

Multiple regression analysis with Burnout as dependent variable

\begin{tabular}{|c|c|c|c|c|c|c|c|c|}
\hline & \multicolumn{2}{|c|}{$\begin{array}{l}\text { UNSTANDARDISED } \\
\text { COEFFICIENTS }\end{array}$} & \multirow[t]{2}{*}{$\begin{array}{l}\text { STANDARDISED } \\
\text { COEFFICIENTS }\end{array}$} & \multirow[t]{2}{*}{$t$} & \multirow[t]{2}{*}{$p$} & \multirow[t]{2}{*}{$F$} & \multirow[t]{2}{*}{$R^{2}$} & \multirow[t]{2}{*}{$\Delta R^{2}$} \\
\hline & B & SE & & & & & & \\
\hline Summary & & & & & & $27.38^{*}$ & 0.4 & 0.54 \\
\hline (Constant) & -17.20 & 2.74 & & -6.28 & & & & \\
\hline Competing Management Goals & -0.01 & 0.14 & -0.01 & -0.07 & 0.942 & & & \\
\hline Work Overload & 0.55 & 0.14 & 0.31 & 4.07 & $0.000^{*}$ & & & \\
\hline Electronic Performance Monitoring & -0.03 & 0.15 & -0.02 & -0.22 & 0.828 & & & \\
\hline Lack of Career Opportunities & 0.51 & 0.14 & 0.28 & 3.61 & $0.000^{*}$ & & & \\
\hline Skill Variety & 0.44 & 0.15 & 0.21 & 2.89 & $0.004^{*}$ & & & \\
\hline Emotional Labour & 0.47 & 0.16 & 0.19 & 2.92 & $0.004^{*}$ & & & \\
\hline
\end{tabular}

${ }^{*} p<0.05-$ statistically significant

magnitude of the correlations, it is clear that lack of career and job opportunities correlated most with affective commitment $(r=-0.46$, large effect). The following medium effects can be reported. In descending order: competing management goals $(r=-0.40)$, lack of skill variety $(r=-0.39)$, work overload $(r-0.35)$ electronic performance monitoring $(r=-0.30)$ and emotional labour $(r=-0.29)$

Positive correlations were found between the independent variables and turnover intentions. The variables that had the greatest influence on turnover intentions were lack of career opportunities ( $r=0.66$, large effect), lack of skill variety ( $r=0.46$, large effect) and work overload ( $r=0.44$, large effect). The variables with a medium effect were electronic performance monitoring $(r=0.32)$, emotional labour $(r=0.31)$ and competing management goals $(r=0.27)$.

With regard to correlation among the dependent variables, practically significant large effects were found between burnout and affective commitment $(r=-0.50)$ and burnout and turnover intentions $(r=0.64)$. A large negative correlation was found between affective commitment and turnover intentions $(r=-0.51)$.

\section{Multiple regression analysis}

Multiple regression analysis was used to assist our understanding of the relative influence that each of the six independent variables had on the dependent variables. In the first regression analysis, all six independent variables were entered simultaneously into the regression model to determine their predictive ability on burnout. The aim was to determine the most significant predictors, so that those that did not relate significantly could be eliminated from subsequent analyses.

The results of a multiple regression analysis with burnout as dependent variable are shown in Table 3.

Table 3 shows that the specified model predicts 54\% of the variance in burnout. Four variables made a significant contribution to the regression model as revealed by the $\mathrm{t}$ values: work overload $(t=4.07, p<0.001)$, lack of career opportunities $(t=3.61, p<0.001)$, skill variety $(t=2.89, p<0.005)$ and emotional labour $(t=2.92, p<0.005)$. The standardised regression coefficients for each of the predictors were: work overload $(\beta=0.31)$, lack of career opportunities $(\beta=0.28)$, skill variety $(\beta=0.21)$, and emotional labour $(\beta=0.19)$. It is clear that work overload and lack of career and job opportunities were the strongest contributors to burnout. This was confirmed through hierarchical regression analysis in which each of the four independent predictors was entered separately in the order of their standardised $\beta$ values, to determine their relative predictive value with regard to burnout. The change in $R^{2}$ for work overload was $35 \%$, followed by lack of career opportunities $13 \%$, skill variety $3 \%$ and emotional labour $3 \%$. Hypothesis 1 is therefore accepted for these variables.

The next question the researchers wanted to answer concerned determining whether affective commitment played a mediating role between burnout and turnover intentions. To answer this question, three conditions had to be met for a variable to be considered as a mediator (Baron \& Kenny, 1986).

In the first of the conditions, the predictor (burnout) had to be significantly related to the hypothesised mediator (affective commitment) (Baron \& Kenny, 1986). This relationship was tested by means of a hierarchical regression analysis. The analysis revealed that burnout was significantly related to affective commitment, as it predicted $25.4 \%$ of the variance in burnout $(\beta=-0.50)(t=6.99, p<0.001)$. This finding provides support for hypothesis 2 .

In the second of the conditions, the predictor had to be significantly related to the outcome variable (turnover intention). The results of a multiple regression analysis with affective commitment and burnout as in dependent variables and turnover as dependent variable are shown in Table 4.

Table 4 shows that burnout was significantly related to turnover intention, as it predicted $41 \%$ of the variance in turnover intention $(\beta=0.64)(t=10.04, p<0.001)$. This finding provides support for hypothesis 3 . 
TABLE 4

Multiple regression analysis with Affective Commitment and Burnout as the independent variables and Turnover Intentions as the dependent variable

\begin{tabular}{|c|c|c|c|c|c|c|c|c|c|}
\hline \multirow{2}{*}{\multicolumn{2}{|c|}{ MODEL }} & \multicolumn{2}{|c|}{$\begin{array}{l}\text { UNSTANDARDISED } \\
\text { COEFFICIENTS } \\
\end{array}$} & $\begin{array}{l}\text { STANDARDISED } \\
\text { COEFFICIENTS }\end{array}$ & \multirow[t]{2}{*}{$t$} & \multirow[t]{2}{*}{$p$} & \multirow[t]{2}{*}{$F$} & \multirow[t]{2}{*}{$R^{2}$} & \multirow[t]{2}{*}{$\Delta R^{2}$} \\
\hline & & & SE & Beta & & & & & \\
\hline \multirow[t]{3}{*}{1} & Summary & & & & & & $100.82^{*}$ & 0.41 & $0.41^{*}$ \\
\hline & (Constant) & 6.25 & 0.54 & & $11.68^{*}$ & & & & \\
\hline & Burnout & 0.31 & 0.03 & 0.64 & 10.04 & $0.000^{*}$ & & & \\
\hline \multirow[t]{4}{*}{2} & Summary & & & & & & $60.33^{*}$ & 0.46 & $0.05^{*}$ \\
\hline & (Constant) & 11.03 & 1.47 & & $7.51^{*}$ & & & & \\
\hline & Burnout & 0.25 & 0.03 & 0.52 & 7.25 & $0.000^{*}$ & & & \\
\hline & Affective Commitment & -0.24 & 0.07 & -0.25 & -3.48 & $0.001^{*}$ & & & \\
\hline
\end{tabular}

${ }^{*} p<0.05$ - statistically significant

In the third of the conditions, the mediator (affective commitment) had to be significantly related to the outcome (turnover intention). Table 2 revealed that affective commitment is statistically significantly related to turnover intention $(r=0.64 ; p<0.001)$.

When affective commitment was added to the model, the predictive value of the model was $46 \%$. Based on the standardised coefficient ( $\beta$ ), the $t$ value and a significance level of $(p<0.05)$, the initial value of burnout was reduced to $(\beta=0.52)$ $(t=7.25, p<0.001)$, but it remained a significant predictor of turnover intentions. Therefore we can conclude that affective commitment partially mediates the relationship between burnout and turnover intention. This finding provides partial support for hypothesis 4

\section{DISCUSSION}

The first aim of this study was to investigate the relationship between six salient work characteristics that are typical of call centres and burnout. All six independent variables were significantly associated with the experience of burnout. Burnout in this call centre is therefore associated with lack of career opportunities, work overload, lack of skill variety, emotional labour, electronic performance monitoring and competing management goals. With regard to their unique and independent contribution, work overload, lack of career opportunities, skill variety and emotional labour were found to be the most important predictors of burnout.

Work overload was consistently found to be a very strong predictor of burnout in call centres (Bakker et al., 2003). The perception of having too many demands can drain an individual's energy (Maslach et al., 2001). In call centres, many things accumulatively work together to create these perceptions. There is consistent pressure to take more calls, which increases the frequency of interpersonal interactions; to complete calls within a given time (limited average call handling time can lead to the perception that the client interaction cannot be completed in the allocated time); and to reduce wrap-up time so that more calls can be taken. Customer service representatives also have to deal with periods of uncontrollable high call traffic during which they need to face clients without a break or time out. This can result in high demands being placed on the role they play, which could deplete their energy (Cordes \& Dougherty, 1993; Deery et al., 2002; Deery et al., 2004; Holman, 2004; Singh, 2000. Zapf et al., 2003)

The different analyses all point to the central role that the lack of career opportunities plays in call centres. The correlational analysis indicated that this had a marked effect on burnout, affective commitment and turnover intentions. It even had a stronger association with burnout than with work overload, which is commonly accepted as one of the major contributors to burnout.
Lack of career and job opportunities and its association with burnout within call centres was corroborated in previous research (Deery et al., 2002). Its presence in call centres is due to the relatively flat organisational structure of call centres, which could contribute to the perception of limited career opportunities. Career advancement and development can be seen as a resource and, if present, would act as a buffer against the development of burnout (Deery et al., 2002; Deery et al., 2004). Another possible explanation that could account for its powerful influence on burnout is found in the work of Pines (1993). Her argument is that people tend to look for existential purpose in their lives. As religion does not fulfil this purpose anymore, people seek meaning through their involvement in their work. Thus, they have very high expectations of their work. When these expectations are not met, it can contribute to the development of burnout (Pines, 1993).

This study supports the idea that call centre jobs with a low level of skill variety are positively linked to the development of burnout. Previous research has shown that jobs that are perceived to be repetitive and routinised with little task variety are linked to the development of burnout. This is specifically true in call centres where job routinisation was linked to burnout (Deery et al., 2002; Zapf et al., 2003).

Emotional labour, and more specifically the emotional dissonance component of emotional labour, was previously linked to burnout in call centres (Zapf et al., 2003). Erickson and Wharton (1997) provide a general explanation of the process by which emotional labour leads to burnout. According to their explanation, emotional labour can be seen as a type of organisational stressor that can eventually lead to the development of burnout (Erickson \& Wharton., 1997). To perform emotional labour requires a degree of effort. The effort comes from the requirement (it could be viewed as a form of demand) to display expected emotions, which could involve the suppression of inappropriate emotions, or even to change the emotions that the customer service representative is experiencing at the time. As Erickson and Wharton state: "... there is effort involved in directing and managing feeling..." (1997, p. 190.)

Emotional work causes service employees to become alienated or estranged from their genuine feelings, with harmful consequences to their psychological well-being (Erickson \& Wharton, 1997). The harmful consequences are thought to be brought about by the depletion of psychological energy and therefore are usually associated with higher levels of emotional exhaustion, one of the core concepts of job burnout. Thus, burnout is thought to be one of the major psychological risk factors associated with the performance of emotional labour (Erickson \& Wharton, 1997).

According to Zapf et al. (2003), customer service representatives are expected to avoid showing any form of negative emotion towards customers and to remain friendly and polite in spite 
of how they really feel. Emotional dissonance therefore seems to be higher in call centres. Lewig and Dollard (2003) made a similar finding, namely that emotional dissonance is the most stressful aspect of emotional work and that emotional exhaustion is predicted via emotional dissonance.

Electronic performance monitoring and surveillance associated positively with burnout (medium effect), but did not emerge as an independent predictor in the regression analysis. One possible explanation for this result is that customer service representatives do not experience its application as invasive and punitive, but rather as part of a development process in which the information is used as feedback for them to improve their performance (Holman, 2004). Another possible explanation might be that customer service representatives see this as a possible work demand and a form of role overload, hence the relatively high association between role overload and electronic performance monitoring.

Competing management goals, although positively and significantly associated with burnout (medium effect), did not emerge as a significant predictor of burnout in this sample. A possible explanation for this could be that customer service representatives see management's demands for higher customer throughput (increased number of calls) and for the reduction of wrap-up time at the cost of service quality more like a job demand in the form of role overload, hence the high association between work overload and competing management goals. Therefore it is speculated that the influence of competing management goals on burnout might be seen as a demand that would increase perceptions of work overload rather than contribute independently to burnout.

The second aim of the study was to examine whether affective commitment mediated the relationship between burnout and turnover intention. The results showed that burnout was statistically significantly related to affective commitment. It is clear that burnout erodes the emotional attachment of customer service employees to the call centre (Lee \& Ashforth, 1996). Furthermore, burnout was also statistically significantly related to turnover intention. As showed by Burke and Richardsen (2001), customer service employees who experience emotional exhaustion indeed seem more likely to think about quitting their jobs. Customer service employees, who experience lower levels of organisational commitment, will also think of leaving their organisation. This confirms the findings of Meyer (2001) and Low et al. (2001) that affective commitment leads to turnover intentions. The negative relationship between affective commitment and turnover intentions found in this study is in line with the finding of De Ruyter (2001, cited in Bakker, Demerouti \& Schaufeli, 2003).

Based on the results of this study, it can be concluded that affective commitment partially mediated the relationship between burnout and turnover intention. This result implies that burnout has a direct effect on turnover intentions. However burnout also affects turnover intentions indirectly through its effect on affective organisational commitment. Therefore, turnover intentions can be better understood by considering burnout and affective organisational commitment.

This study was not without its limitations. The measurement of variables was based on self-report measures, which could lead to common method variance between predictor variables and outcome variables. The study was also restricted in its scope, as it only focused on six of the more salient characteristics that reflect the inherent nature of call centre work. Many other variables that have been suggested in previous research play a role in the development of burnout in call centres. The sample size in the present study was small and came from only one call centre. The research should be replicated with a bigger sample ranging across different call centres. This will increase the generalisability of the results. It is therefore suggested that these results be used cautiously.

\section{Recommendations}

Based on the findings of this research, some practical recommendations can be made for the management of call centres to reduce the development of burnout and turnover intentions. The first recommendation is to redesign the work of customer service representatives according to sound principles of job design and job enrichment to create meaningful tasks with different levels of skill variety built into the work. This will facilitate challenging and interesting work. It will also provide employees with the opportunity to vary their work and to do other types of tasks as well (Frenkel et al., 1998; Zapf et al., 2003). The second recommendation is to allow customer service representatives more time with their customers on the phone (increase average handling time) to reduce the perception of work overload in the form of time pressure. This has been found to reduce the development of burnout (Deery et al., 2002).

The third recommendation is to define a career path for customer service representatives, which should not be based on upward career movement only, but also on lateral movement, so that they can gain experience in different departments of the organisation or the call centre. A career cycle of two years on the phone and one year off the phone could be tried and may prove beneficial for the reduction of burnout and turnover intentions. The company could establish an internal promotion policy simultaneously, which might influence affective commitment.

\section{REFERENCES}

Bakker, A.B., Demerouti, E. \& Schaufeli, W.B. (2003). Dual processes at work in a call centre: An application of the job demands-resources model. European Journal of Work and Organizational Psychology, 12(4), 393-417.

Baron, R.M. \& Kenny, D.A. (1986). The moderator-mediator variable distinction in social psychological research: Conceptual, strategic and statistical considerations. Journal of Personality and Social Psychology, 51(6), 1173-1182.

Bozeman, D.P. \& Perrewé, P.L. (2001). The effect of item content overlap on organizational commitment questionnaireturnover cognition relationships. Journal of Applied Psychology, 86(1), 161-173.

Briggs, A. (1998). The 1998 South African call centre benchmarking report. The Merchants Group.

Burke, R.J. \& Richardsen, A.M. (2001). Psychological burnout in organizations: Research and intervention. In R.T. Golembiewski (Ed.). Handbook of organizational behavior (2nd Ed). New York: Marcel Dekker, pp. 327-363.

Cordes, C.L. \& Dougherty, T.W. (1993). A review and an integration of research on job burnout. Academy of Management Review, 18(4), 621-656.

Deery, S., Iverson, R. \& Walsh, J. (2002). Work relationships in telephone call centres: Understanding emotional exhaustion and employee withdrawal. Journal of Management Studies, 39(4), 471-496.

Deery, S., Iverson, R. \& Walsh, J. (2004). The effect of customer service encounters on job satisfaction and emotional exhaustion. In S. Deery \& N. Kinnie (Eds.). Call centres and human resource management: A cross-national perspective. New York: Palgrave Macmillan, pp. 201-221.

Deery, S. \& Kinnie, N. (2004). Introduction: The nature and management of call centre work. In S. Deery \& N. Kinnie (Eds.). Call centres and human resource management: A crossnational perspective. New York: Palgrave Macmillan, pp. 1-21.

Dunham, R.B., Grube, J.A. \& Castañeda, M.B. (1994). Organizational commitment: The utility of an integrative definition. Journal of Applied Psychology, 79(3), 370-380. 
Erickson, R.J. \& Wharton, A.S. (1997). Inauthenticity and depression. Work and Occupations, 24(2), 188-214.

Frenkel, S.J., Tam, M., Korczynski, M. \& Shire, K. (1998). Beyond bureaucracy? Work organization in call centres. The International Journal of Human Resource Management, 9(6), 957-979.

Grandey, A.A. (2000). Emotion regulation in the workplace: A new way to conceptualize emotional labor. Journal of Occupational Health Psychology, 5(1), 59-100.

Grebner, S., Semmer, N.K., Faso, L.L., Gut, S., Kälin, W. \& Elfering, A. (2003). Working conditions, well-being, and jobrelated attitudes among call centre agents. European Journal of Work and Organizational Psychology, 12, 341-365.

Holdsworth, L. \& Cartwright, S. (2003). Empowerment, stress and satisfaction: An exploratory study of a call centre. Leadership and Organization Development Journal, 24(3), 131-140.

Holman, D. (2004). Employee well-being in call centres. In S. Deery \& N. Kinnie (Eds.). Call centres and human resource management: A cross-national perspective. New York: Palgrave Macmillan, pp. 223-245.

Holmbeck, G.N. (1997). Toward terminological, conceptual, and statistical clarity in the study of mediators and moderators: Examples from the child-clinical and paediatric psychology literatures. Journal of Consulting and Clinical Literatures, 65, 559-610.

Janssen, P.M., De Jonge, J. \& Nijhuis, F.J.N. (2001). Specific relationships between work characteristics and intrinsic motivation, burnout and turnover intention: A multisample analysis. European Journal of Work and Organizational Psychology, 10(1), 1-23.

Kruml, S.M. \& Geddes, D. (2000). Exploring the dimensions of emotional labour. Management Communications Quarterly, 14(1), 8-50

Lee, R.T. \& Ashforth, B.E. (1996). A meta-analytic examination of the correlates of the three dimensions of job burnout. Journal of Applied Psychology, 81, 123-133.

Leiter, M.P. \& Maslach, C. (1988). The impact of interpersonal environment on burnout and organizational commitment. Journal of Organizational Behaviour, 9(4), 297-308.

Lewig, K.A. \& Dollard, M.F. (2003). Emotional dissonance, emotional exhaustion and job satisfaction in call centre workers. European Journal of Work and Organizational Psychology, 12(4), 366-392.

Low, G.S., Cravens, D.W., Grant, K. \& Moncrief, W.C. (2001). Antecedents and consequences of salesperson burnout. European Journal of Marketing, 35(5/6), 587-611.

Maertz, C.P. \& Campion, M.A. (2001). 25 Years of voluntary turnover research: A review and critique. In I. Robertson \& C. Cooper (Eds.). Personnel psychology and HRM: A reader for students and practitioners. New York: Wiley, pp. 343-375.

Malhotra, N. \& Mukherjee, A. (2004). The relative influence of organisational commitment and job satisfaction on service quality of customer-contact employees in banking call centres. Journal of Services Marketing, 18(3), 162-174.

Maslach, C. \& Leiter, M.P. (1997). The truth about burnout: How organizations cause personal stress and what to do about it. San Francisco, CA: Jossey-Bass.

Maslach, C., Schaufeli, W.B. \& Leiter, M.P. (2001). Job burnout. Annual Review of Psychology, 52, 397-422.

Meyer, J.P. (2001). Organisational commitment. In I. Robertson \& C. Cooper (Eds.). Personnel psychology and HRM: A reader for students and practitioners. New York: Wiley, pp. 289-342.

Morris, J.A. \& Feldman, D.C. (1996). The dimensions, antecedents, and consequences of emotional labor. Academy of Management Review, 21(4), 986-1011.

Mowday, R.T.,Steers, R.M.\&Porter, L.W.(1979). The measurement of organizational commitment. Journal of Vocational Behavior, $14(2), 224-247$

Nunnally, J. \& Bernstein, I.H. (1994). Psychometric theory (3rd Ed.) New York: McGraw-Hill.

Pines, A.M. (1993). Burnout. In L. Goldberger \& S. Breznitz (Eds.). Handbook of stress: Theoretical and clinical aspects (2nd Ed.). New York: The Free Press, pp. 86-402.

Schutte, N., Toppinen, S., Kalimo, R. \& Schaufeli, W.B. (2000). The factorial validity of the Maslach Burnout InventoryGeneral Survey (MBI-GS) across occupational groups and nations. Journal of Occupational E Organizational Psychology, 73(1), 53-67.

Singh, J. (2000). Performance productivity and quality of frontline employees in service organizations. Journal of Marketing Research, 64(2), 15-35.

Singh, J. \& Goolsby, J.R. (1994). Behavioral and psychological consequences of boundary-spanning burnout for customer service representatives. Journal of Marketing Research, 94, $558-570$.

Somers, M.J. (1995). Organizational commitment, turnover and absenteeism: an examination of direct and interaction effects. Journal of Organizational Behaviour, 16, 49-58.

SPSS (2007). SPSS 14.0 for Windows. Chicago, IL: SPSS Incorporated.

Steyn, H.S. (1999). Praktiese betekenisvolheid: Die gebruik van effekgrootes. Wetenskaplike bydraes - Reeks B: Natuurwetenskappe Nr. 117. Potchefstroom: PU vir CHO.

Taylor, P. \& Bain, P. (1999). An assembly line in the head: work and employee relations in the call centre. Industrial Relations Journal, 30(2), 101-117.

Taylor, P., Hyman, J., Mulvey, G. \& Bain, P. (2002). Work organization, control and the experience of work in call centres. Work, Employment and Society, 16(1), 133-150.

Wallace, C.M., Eagleson, G. \& Waldersee, R. (2000). The sacrificial HR strategy in call centres. International Journal of Service Industry Management, 11(2), 174-184.

Zapf, P.F., Isic, A., Bechtoldt, M. \& Blau, P. (2003). What is typical for call centre jobs? Job characteristics and service interactions in different call centres. European Journal of Work and Organizational Psychology, 12(4), 311-340. 